
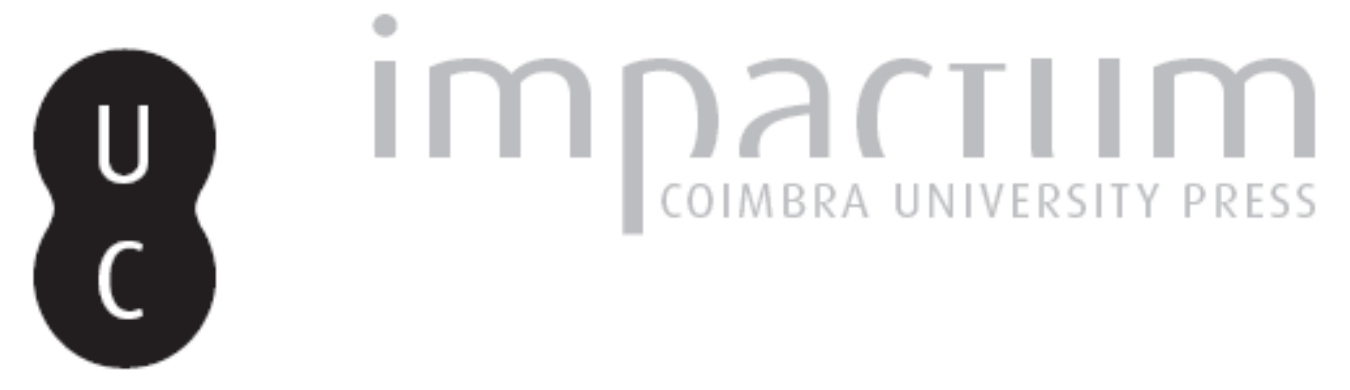

\title{
Akhenaton: realidade e representações
}

Autor(es): Carreira, Paulo

Publicado por: Centro de História da Universidade de Lisboa

URL persistente:

URI:http://hdl.handle.net/10316.2/23716

DOI:

DOI:http://dx.doi.org/10.14195/0871-9527_20_4

Accessed : $\quad$ 26-Apr-2023 10:51:21

A navegação consulta e descarregamento dos títulos inseridos nas Bibliotecas Digitais UC Digitalis, UC Pombalina e UC Impactum, pressupõem a aceitação plena e sem reservas dos Termos e Condições de Uso destas Bibliotecas Digitais, disponíveis em https://digitalis.uc.pt/pt-pt/termos.

Conforme exposto nos referidos Termos e Condições de Uso, o descarregamento de títulos de acesso restrito requer uma licença válida de autorização devendo o utilizador aceder ao(s) documento(s) a partir de um endereço de IP da instituição detentora da supramencionada licença.

Ao utilizador é apenas permitido o descarregamento para uso pessoal, pelo que o emprego do(s) título(s) descarregado(s) para outro fim, designadamente comercial, carece de autorização do respetivo autor ou editor da obra.

Na medida em que todas as obras da UC Digitalis se encontram protegidas pelo Código do Direito de Autor e Direitos Conexos e demais legislação aplicável, toda a cópia, parcial ou total, deste documento, nos casos em que é legalmente admitida, deverá conter ou fazer-se acompanhar por este aviso.

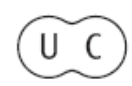




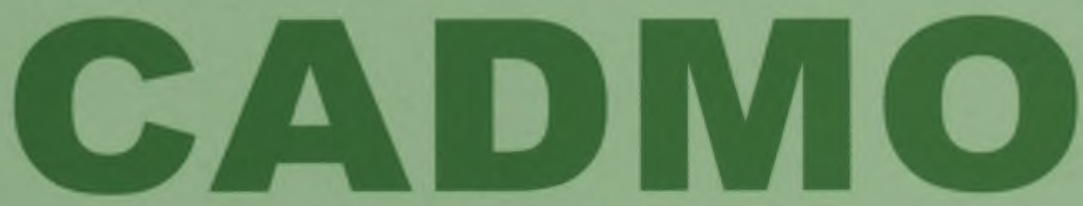

Revista de História Antiga

\author{
Centro de História \\ da Universidade de Lisboa
}

\title{
20
}

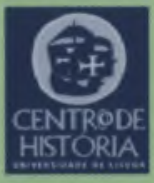

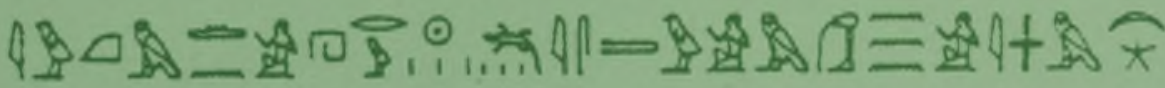

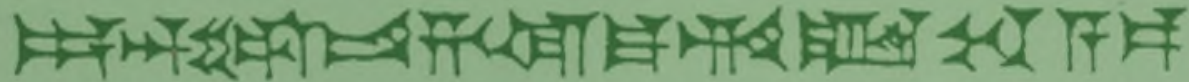

MHNIN AEI $\Delta$ E $\Theta E A ~ \Pi H \Lambda H I A \triangle E \Omega$ 


\title{
AKHENATON. REALIDADE E REPRESENTAÇÕES
}

\author{
PAULO CARREIRA
}

Universidade de Lisboa borgescarreira@sapo.pt

\section{Resumo}

Inserindo-se embora nas correntes estético-teológicas predominantes no reinado de Amen-hotep III, a iconografia de Akhenaton é levada a extremos que traduzem formas de pensamento nem sempre totalmente acessíveis. Durante muito tempo, o corpo do rei foi objecto de uma leitura patológica que recentes estudos de ADN mostraram ser errónea. Esses mesmos estudos vieram, no entanto, lançar uma extrema confusão em tudo o que anteriormente se admitia sobre a cronologia deste reinado, situação que terá de ser clarificada pelos egiptólogos.

A análise de um conjunto de cenas envolvendo Akhenaton e a sua família mostrou que ele era a figura predominante a partir da qual todas as outras personagens se definiam. Esta conclusão está de acordo com os textos da época.

Palavras-chave: Amen-hotep III; Akhenaton; arte de Amarna; estudos de ADN.

\begin{abstract}
Arising from aesthetics and theology from the times of Amenhotep III, the iconography of Akhenaten was taken to such extremes that may reflect ways of thinking which cannot be fully understood nowadays. The king's body has been read for a long time as pathological but this was not corroborated from very recent DNA analysis. Those have clarified much doubts about some links on the royal family but led to extreme confusion on longtime accepted chronology of Akhenaten's reign.
\end{abstract}


Correlation analysis of scenes concerning the king and the royal family has shown that he was the main person from whom the other people was defined. This conclusion is supported by contemporaneous texts.

Keywords: Amenhotep III; Akhenaten; amarnian art; DNA analysis.

\section{Pontos de partida}

Para compreender o caso específico da arte de Amarna, é necessário fazer primeiramente uma breve análise da arte egípcia que a antecedeu, mostrando depois as novidades introduzidas no tempo de Amen-hotep III e desenvolvidas no reinado de Akhenaton, seu filho e sucessor.

A representação egípcia de figuras humanas ou animais fazia-se recorrendo a critérios bidimensionais muito específicos. Pretendia-se o máximo de informação por meio de uma só vista e deste modo, a tridimensionalidade dos corpos exprimia-se numa interpretação aspectiva. Assim, as mesas de oferendas eram vistas de lado mas com um empiIhamento de bens que ilustrava o muito que era dado e que igualmente se quantificava em textos explicativos. Uma cena de batalha podia mostrar as suas várias fases na mesma imagem.

A altura do corpo variava com a posição social. Ninguém podia exceder a altura do rei que era igual à dos deuses, sendo a rainha da mesma estatura ou mais baixa. Quaisquer outros intervenientes eram pequenos e podiam mesmo estar curvados. Os cativos acocoravam-se no chão, erguendo as mãos num pedido de misericórdia. Cada gesto era convencionado e muitas vezes podia ser lido como um hieróglifo(1).

Tradicionalmente, os relevos e pinturas egípcias resultavam da transposição para a pedra ou para uma superíície especialmente preparada, de desenhos elaborados a partir de um sistema de regras muito preciso(2). Era primeiramente esboçado um conjunto de linhas horizontais e paralelas que definiam a posição dos vários pontos do corpo. Este sistema evoluiu para redes quadriculadas (fig. A1). A primeira apareceu no Império Médio ${ }^{(3)}$, ocupando a personagem um total de 18 quadrados, medidos a partir do nível do solo até à sobrancelha. A partir da XXV dinastia, esta grelha foi substituida por uma outra de 21 quadrados e a altura do representado, medida até à zona superior do olho. Houve no entanto, desvios, por exemplo, durante a segunda década do reinado de Amen-hotep III (XVIII dinastia) cujas imagens 
mostram um alongamento das pernas. Akhenaton alterou igualmente o sistema com a adição de dois ${ }^{(4)}$ ou quatro(5) quadrados acima do joeIho, o que provocou o aumento da visibilidade da parte superior do corpo em detrimento da inferior ${ }^{(6)}$.

\section{A arte no tempo de Amen-hotep III}

O reinado de Amen-hotep ill foi uma época de paz, de joie de vivre, para os que dela puderam gozar ${ }^{(7)}$. Foi também uma altura em que o pensamento, nomeadamente o pensamento teológico se desenvolveu bastante, tal como se prova nos textos e na iconografia. Esta não se mantém constante ao longo ao longo do reinado e, mormente na sua última fase, contém já muito do que vai ser a futura arte amarniana $^{(8)}$. Depois da celebração terceiro jubileu, Amen-hotep III é completamente transfigurado, rejuvenesceu, o olho prolongado e obliquo ocupa grande parte do rosto (fig. A2). O traje é enriquecido com elementos solares e osiríacos ${ }^{(9)}$. Com o incremento da sua parte divina, o rei parece afastar-se cada vez mais da humanidade, tornou-se mesmo uma representação codificada do disco solar (fig. A3). No decorrer do Heb-sed, Amen-hotep III/Aton e Tié/Hathor, casal solar por excelência tomaram lugar numa barca puxada à sirga pelos seus fiéis cortesãos e reproduzem na terra o celestial percurso do deus:

"(Os membros da corte) foram conduzidos ao lago de sua majestade para remar na barca do rei (...) eles agarraram os cabos de reboque da barca da noite e o cabo da proa da barca da manhã, e puxaram as barcas até ao grande lugar. Detiveram-se diante dos degraus do trono.

Foi sua majestade quem fez isto de acordo com os escritos das antigas gerações [do] povo uma vez que, desde o tempo dos antepassados, nunca se tinham celebrado [estes] rituais do jubileu.»(10)

\section{A representação de Amen-hotep IV/Akhenaton}

A iconografia de Akhenaton está na sequência do estilo da última década de Amen-hotep III, mas essa mesma continuidade foi levada a extremos tais, que deve ter confundido a mentalidade tradicional do seu povo. No início do reinado, Akhenaton é visto como um adolescente (fig. A4) e como tal representado, mas, cerca de dois anos 
depois, a sua imagem atinge as raias do grotesco, porventura de um modo deliberado: rosto alongado, seios desenvolvidos, ancas femininas, nádegas salientes e grossas coxas. O escultor Bek, autor destas obras, lava daqui as suas mãos, afirma peremptoriamente que as executou a mandado do rei, foi ensinado por ele:

«Prestando adoração ao senhor das Duas Terras, beijando o solo perante o (filho) único de Ré, pelo intendente dos trabalhos na montanha vermelha, o discípulo a quem sua majestade, ele mesmo, instruiu, o chefe dos escultores nos muitos e grandes monumentos do rei na casa de Aton, no Horizonte de Aton, Bek, filho do chefe dos escultores Men, nascido da dona de casa Rui, de Heliópolis." (11)

Um caso extremo está representado na fig. A5. Mostra alguém com os restos de uma coroa mas sem o toucado nemsit, munido das insígnias do faraonato como o ceptro heka, o ceptro nekhakha, e a barba postiça, e marcado com as habituais duas cartelas do nome de Aton. O corpo é inteiramente feminino, embora o triângulo púbico não esteja assinalado, como em muitas outras estátuas da época. Para Julia Samson ${ }^{(12)}$ podemos estar perante uma representação da rainha: «The breasts are carved more like those of a woman, although Akhenaten was plump-chested. It must have been one of several colossal statues of Nefertiti. ... Presumably this nude feminine figure was to have been finished as Nefertiti, wearing her open robe and the tall crown of the kings of the kings of a united Egypt, a part of which remains on the statue" ${ }^{(13)}$.

Joyce Tyldesley(14) assinala a extraordinária parecença entre a estátua e os colossos do Gempaaton e levanta duas hipóteses: ou a estátua não passa de um modelo para qualquer outra, do rei ou da rainha, ou deverá ter uma leitura teológica. De acordo com os Hinos de Aton, o deus é duplamente sexuado, pai/mãe. Como até hoje não foi encontrada nenhuma obra semelhante, as duas hipóteses parecem igualmente possíveis.

Há um grande contraste entre as agressivas produções artísticas de Bek e outras, mais tardias, provenientes da oficina de Tutmés ${ }^{(15)}$ que são bastante mais suaves e realistas. No entanto, o mesmo Tutmés realizou estranhas estátuas de princesas que associam rostos belos e serenos e crânios completamente deformados. Deformação artificial, semelhante à provocada em certas tribos africanas e na América do Sul, mas de que não temos provas no Egipto? Se assim é, por que razão Ankhesenpaaton apresenta uma cabeça normal, no estado adulto? 
Dorothea Arnold ${ }^{(16)}$ propõe a hipótese de a forma ovóide do crânio ter igualmente um significado teológico: o ovo seria um símbolo da criação nos Hinos a Aton que, na realidade, o apresentam de uma forma "científica" e não simbólica. Uma coisa é certa: alguns funcionários, como Parennefer, não deixaram de se fazer também representar com o crânio alongado(17).

É possível que esta necessidade de "fazer diferente" fosse uma agressão ideológica (e deliberada) a Amon-Ré e se traduzisse em obras acintosamente colocadas nos dois grandes centros do seu poder, Karnak e Lucsor. Akhenaton, imagem terrena de um deus, estava também presente, na morada familiar e na morada eterna dos seus cortesãos porque, mais do que simples referente político, detinha as "chaves" da vida no Além, enquanto detentor único da revelação feita por Aton, seu pai. Como tal, figura nos túmulos de Amarna, acompanhado pela "sagrada família", que é a sua. O tempo de Osíris e do seu tribunal divino tinha passado, os "Textos de $\mathrm{Ai}$ » mostram que a antiga confissão osiríaca passou a ser feita diante dele.

A arte de Amarna continuou porém a utilizar as velhas representações do poder real, o faraó permaneceu esfinge protectora do seu povo, continua a pisar os inimigos do Egipto, simbolizados nos «Nove Arcos" que ornamentam o pavimento do palácio real de Amarna. Também Nefertiti castiga com violência as mulheres inimigas.

\section{O corpo do rei e as suas leituras}

Quando Jean-François Champollion (1790-1832) visitou o túmulo de Akhenaton, em 1829 (ou em 1830), ficou chocado com o aspecto feminino do rei e atribuiu este facto a uma qualquer doença ${ }^{(18)}$. O seu compatriota Eugène Lefébure (1838-1908) foi ainda mais longe. Akhenaton não teria sido um rei mas sim um faraó-mulher, como Hatchepsut, o que concordava com o testemunho de Maneton, citado por Flávio Josefo(19): uma certa Akencheris sucedera no trono do Egipto ao rei Or (Amen-hotep III). Em 1894, Flinders Petrie recusava liminarmente esta hipótese ${ }^{(20)}$ : «It has been proposed that Amenhotep III died after a very few years, and that Akhenaten, a man, or a woman was raised by intrigue into his vacant place, adopted his throne name, and his diadem name, and introduced the new style. It has been proposed that the new ruler was a woman, masquerading with wife and suppositious children; such a notion resting on effeminate plumpness 
of Akhenaten, and the alleged prevalence of feminine courtiers. It has been proposed that he was a eunuch. It is credible that the most uxorious king of Egypt, who appears with his wife on every monument, who rides side by side with her in a chariot, and kisses her in public, who dances her on his knee, who has a steadily increasing family that king was either a woman in masquerade or a eunuch?"

Restava analisar o estranho corpo de Akhenaton segundo o ponto de vista médico, ideia que já estava implícita, como vimos, em Champollion, e iria fazer carreira, dando origem às mais variadas explicações. No seu livro The life and times of Akhnaton, Pharaoh of Egypt, Arthur Weigall(21)avançava um diagnóstico: «It may be, as has been said, that the queen, before the birth of her son, had vowed him to Ra-Horakhti. Again the boy was epileptic, was subject to hallucinations and it may be that while in this condition he had seen visions or uttered words which led his mother to believe him to be the chosen one of the Heliopolitan god, whose name the prince must have been constantly hearing".

Não há qualquer base histórica para a alegada "epilepsia" de Akhenaton. Várias doenças foram propostas para explicar as disformidades do rei. Cyril Aldred, de acordo com especialistas médicos, admitiu que Akhenaton sofreria do chamado síndroma de Frölich, uma disfunção glandular ao nível da hipófise e do tálamo cerebral, que se manifesta principalmente no sexo masculino e na altura da puberdade. A doença caracteriza-se pela atrofia dos órgãos sexuais, acumulação de gordura na região dos seios, ancas e coxas, tal como é patente em várias representações do rei. Esta explicação da sua "disformidade" pelo síndroma de Frölich é pouco provável, uma vez que se sabe provocar esterilidade, coisa que não está de acordo com a numerosa prole que o rei gerou, pelo menos seis filhas de Nefertiti e talvez uma filha com a dama Kia.

Alwyn L. Burridge ${ }^{(22)}$ avançou um novo diagnóstico, o sindroma de Marfan. É provocado por uma mutação do gene fibrilina-1, responsável pela coesão dos tecidos elásticos do corpo (aorta, olhos e pele) e pela ligação entre ossos e músculos. Por acção de mecanismos que ainda não estão compreendidos, dá-se um crescimento exagerado dos ossos longos, o que provoca estatura elevada e dedos alongados (aracnodactilia) . Esta mutação pode ser espontânea ou transmitida hereditariamente. Reflexos do sindroma de Marfan poderiam, segundo Reeves $^{(23)}$, ser aduzidos das imagens do faraó e da sua família. 


\subsection{Estudos de $A D N$ e suas consequências}

O desenvolvimento da biologia molecular e dos conhecimentos acerca do ADN humano, a partir da década de 80 do século passado, tornaram possível a sua aplicação ao estudo das múmias egípcias e, já em 2001, um grupo de investigadores japoneses solicitara o fornecimento de amostras dos ossos, cabelos e unhas de Tutankhamon, o que foi recusado pelo director do Conselho Superior das Antiguidades Egípcias, Zahi Hawass ${ }^{(24)}$. Curiosamente, este acabou mais tarde por chegar a um acordo com a Siemens e o Discovery Channel, com vista a estes mesmos estudos, constituindo-se então o denominado "Family of Tutankhamon Project", com o propósito de clarificar a árvore genealógica do jovem faraó, através do estudo do seu próprio $A D N$ e do ADN pertencente a indivíduos admitidos a priori como seus parentes próximos. Estabeleceram-se duas equipas, uma trabalhando no Museu Egípcio do Cairo e outra na Kasr al-Ainy Faculty of Medicine, nas quais trabalharam, para além do próprio Hawass, onze peritos egípcios e dois consultores estrangeiros, um da Universidade de Tubingen, Alemanha, e um de Bolzano, Itália.

Depois de terem sido efectuadas tomografias de todas as múmias, recolheram-se amostras no corpo de Tutankhamon e em outros dez, cinco de possíveis familiares e cinco de estranhos, para despistagem de erros. De cada uma delas extraíram-se quinze amostras de medula óssea.

Foi traçada a linha paterna, de acordo com sequências específicas do cromossoma $\mathrm{Y}$, e a linha materna através do ADN mitocondrial, que é transmitido pela mãe, embora, de acordo com os autores, o estudo deste último haja produzido resultados inconclusivos.

As conclusões do projecto, publicadas em Fevereiro de 2010 são, no mínimo, surpreendentes, e podem sintetizar-se nos seguintes pontos $^{(25) \text { : }}$

a) A múmia encontrada no KV35, primitivamente designada por "elder lady", é filha biológica de luia e de Thuia - trata-se portanto da rainha Tié.

b) Confirma-se que Akhenaton é filho de Amen-hotep III, cuja múmia foi encontrada no túmulo KV35, e de Tié.

c) A múmia do KV55 pertence, "almost certainly", a Akhenaton. A sua idade na altura da morte estima-se entre 45 e 55 anos $^{(26)}$. Não foi detectado no seu corpo, ou em qualquer dos indivíduos estudados, quaisquer sinais de "sindromas de 
Marfan, de ginecomastia ${ }^{(27)}$ ou de craniossinostose ${ }^{(28)}$ ». Deste modo, segundo estes investigadores, a peculiar iconografia de Akhenaton obedece provavelmente a motivos de ordem político-religiosa. Do mesmo modo, não há motivos de ordem biológica para as deformações cranianas exibidas pelos membros da família real.

d) Akhenaton foi o pai biológico de Tutankhamon.

e) A sua mãe biológica era irmã do rei e foi identificada como a "younger lady" encontrada no KV35. Tinha sido anteriormente considerada como Nefertiti(29).

f) Tutankhamon morreu de malária e talvez de um estado infeccioso generalizado, sendo afastada por completo a ideia de homicídio. O seu corpo exibe uma fractura do fémur e deformação da coluna vertebral (cifoscoliose). Sofria de uma grave doença inflamatória que Ihe destruiu dois metatarsos do pé direito. Isto está perfeitamente de acordo com o facto de ser representado a usar uma muleta e do grande número de bengalas que foi encontrado no seu túmulo.

g) O corpo designado por KV21A foi identificado como pertencendo a sua irmã Ankhesenamon. É a mãe «mais provável» dos dois fetos encontrados no túmulo do seu esposo, claramente identificado como o pai biológico.

A nova árvore genealogia da família de Akhenaton está representada na fig. A6.

\subsubsection{Comentários}

É impossível, no âmbito de um artigo como este, discutir o método experimental utilizado mas, porque também o autor pertenceu à carreira de investigação, poderá chamar a atenção para alguns pontos que se afiguram menos claros.

Estranha-se que não tenha sido efectuado um estudo paralelo num qualquer laboratório estrangeiro, o que valorizaria em muito os resultados obtidos, libertando-os da suspeição de atitudes nacionalistas mais ou menos exacerbadas.

Lamenta-se que as análises de outras múmias deste conjunto não tenham sido divulgadas.

A legitimidade destas questões, que certamente serão clarificadas em futuros artigos, não põem em causa a importância dos resultados 
obtidos, os quais vêm introduzir uma completa subversão em tudo o que julgávamos saber acerca da cronologia da época de Amarna. Isto prende-se com o facto de a idade da morte de Akhenaton ter sido agora colocada entre os 45 e os 55 anos, quando antes se pensava ter ocorrido entre os 30 e os $35^{(30)}$. Admitindo o valor mínimo de 45 anos e uma vez que reinou 17 , teria subido ao trono com 28 . Ora, as suas representações mais antigas, como a do túmulo de Kheruef, TT 92, mostram, não um adulto, mas um adolescente de cerca de 14 anos, na companhia da mãe e não do pai. Se, como também se admite, foi entronizado no ano seguinte, teria 32 anos quando morreu, o que está muito perto dos valores referidos por Hussein e Harris. A menos que tivesse sido forçado a abdicar, falecendo já no reinado de $\mathrm{Ai}$, mas não há quaisquer provas disto. Restaria a velha possibilidade de uma co-regência com Amen-hotep III iniciada cerca de 1367 a. C. Se assim houvesse acontecido, o célebre cerimonial do ano 12, representado nos túmulos dos funcionários Meriré (II) e de Huia, em Amarna, marcaria, de facto, a data da sua coroação como é opinião de vários autores $^{(31)}$. Note-se porém, que na carta EA27, datada de início do ano 2 de Amen-hotep IV, o rei Tusratta diz enviar presentes à esposa do rei, Tadukhepa, e à rainha-mãe, Tié( ${ }^{(32)}$. A ausência do nome de Amen-hotep III só é explicável admitindo que a notícia da sua morte era conhecida no Mitanni. Como não foram encontradas, até agora, provas sólidas e indiscutiveis de uma co-regência, seria do maior interesse determinar a idade com que morreu Amen-hotep III e rever cuidadosamente os resultados relativos a seu filho.

\section{Contextos iconográficos e correlações}

Tal como os seus antecessores, e os reis que the irão suceder, Akhenaton fez-se representar na companhia de deuses, familiares e súbditos. Enquanto se manteve, ou pareceu manter-se, fiel às tradições religiosas, mostrou-se, no acto de cultuar vários netjeru, os quais encara de olhos nos olhos. Esta situação desaparece à medida que a iconografia atonista evolui para representações puramente simbólicas do deus. Uma vez que o filho não é igual ao pai, não pode ser representado com a mesma altura.

Aton só admite uma representação indirecta, um disco solar no qual toda a significância está concentrada na metade inferior, defendida por uma uraeus que ostenta o símbolo da vida (fig. A3). Um feixe de 
raios surge abaixo do diâmetro horizontal e não diverge a partir do centro, mas de um ponto que está para além dele. Isto só tem sentido quando se observam as próprias obras, em vez de simples desenhos. É então perfeitamente claro que estamos perante uma calote esférica, vista de frente nas representações bidimensionais. Deste ponto, algures no interior da esfera solar, emanam raios que terminam em mãos, algumas sustentando o símbolo ankh (vida), o símbolo uase (poder) e até armas com as quais o rei ataca os seus inimigos. Assim encarado, Aton reduz-se à simples hipóstase de Ré, e o atonismo a um prolongamento da teologia de Héliopolis. Diante do seu deus que tudo the dá, Akhenaton eleva os olhos, faz numerosas oferendas, na companhia da família real, e prodigaliza recompensas aos seus fiéis funcionários ${ }^{(33)}$. Para além destas figurações tradicionais, há uma ênfase particular nos "retratos de família», mostrando-se o rei como excelente filho que se banqueteia na companhia da mãe e do pai ${ }^{(31)}$. É o esposo amantíssimo que ternamente enlaça Nefertiti e brinca com as filhas num ambiente de alegrias simples e puras que a luz do Sol ilumina.

Será Akhenaton a figura dominante em volta da qual tudo se constrói? A reposta envolve o estudo das correlações que é possível estabelecer entre as alturas de cada personagem ${ }^{(35)}$.

Partindo de um total de dezanove cenas $^{(36)}$ obtiveram-se as rectas de correlação representadas nas figuras 1-4.

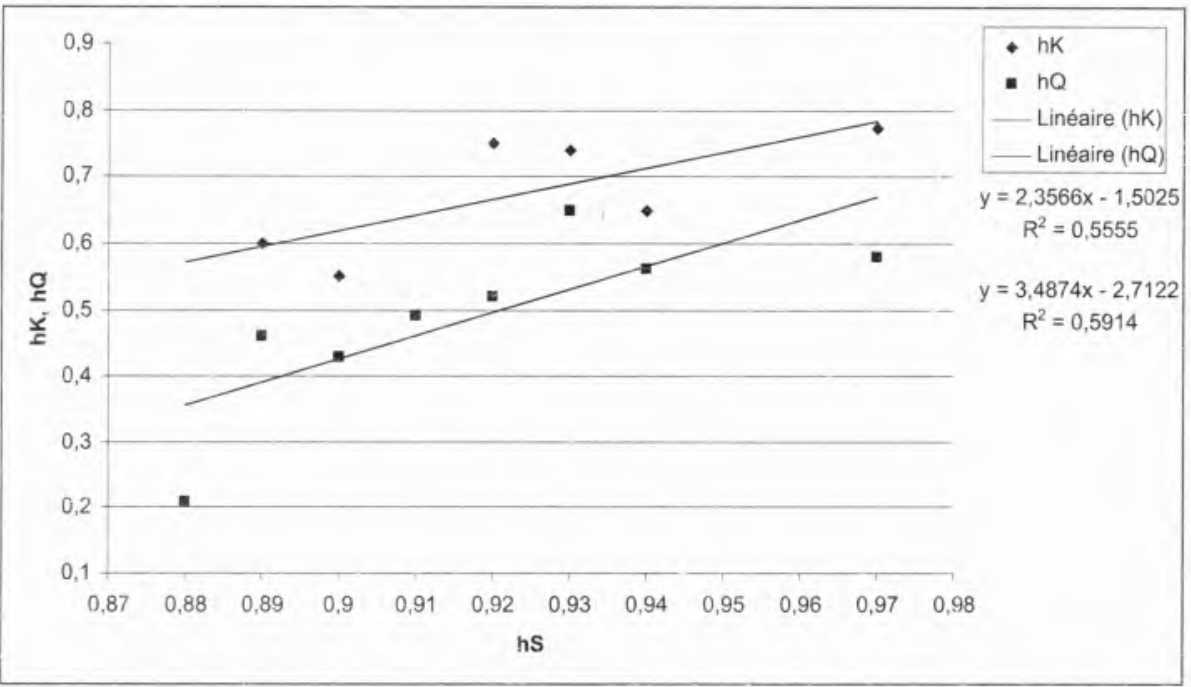

Fig. 1 - Variação das alturas do rei $\left(h_{k}\right)$ e da rainha $\left(h_{0}\right)$ com a altura do disco solar $\left(h_{S}\right)$. A correlação é fraca ${ }^{(37)}$. 


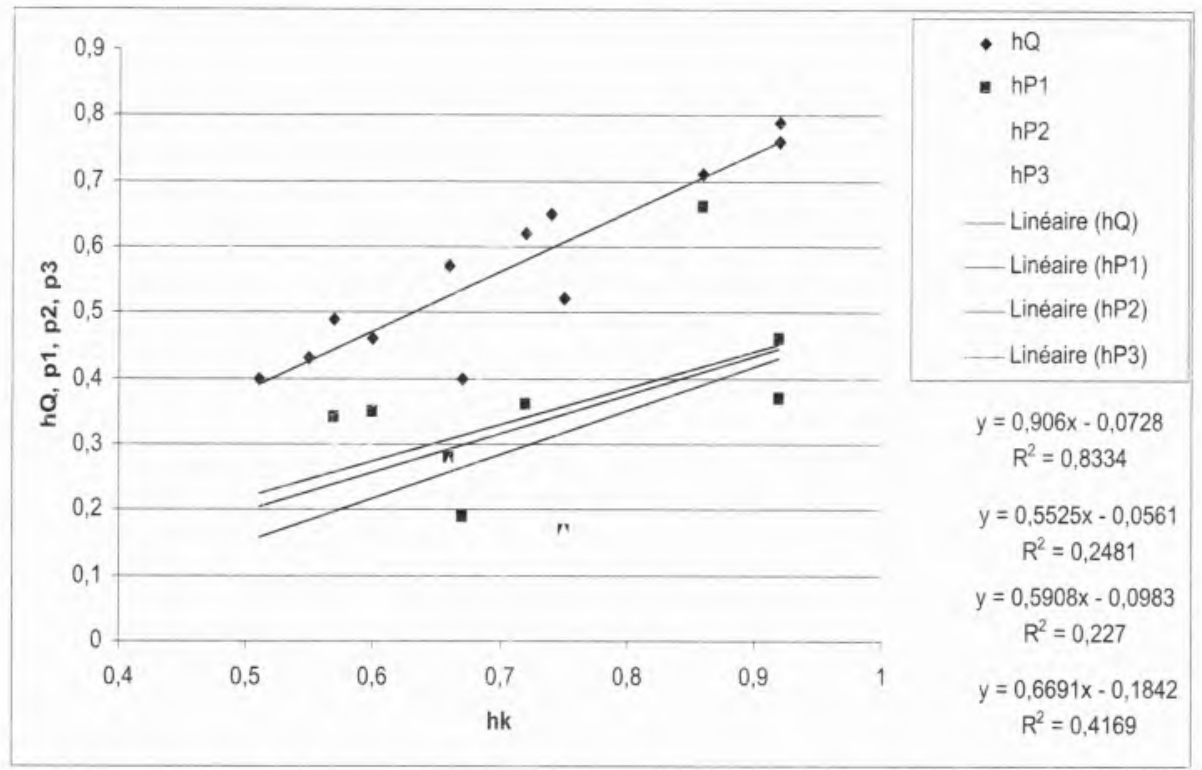

Fig. 2 - Variação da altura da rainha $\left(h_{\rho}\right)$ e das princesas $\left(h_{p}\right)$ em função da altura do rei $\left(h_{k}\right)$. Só existe verdadeira correlação entre a altura do rei e a da rainha.

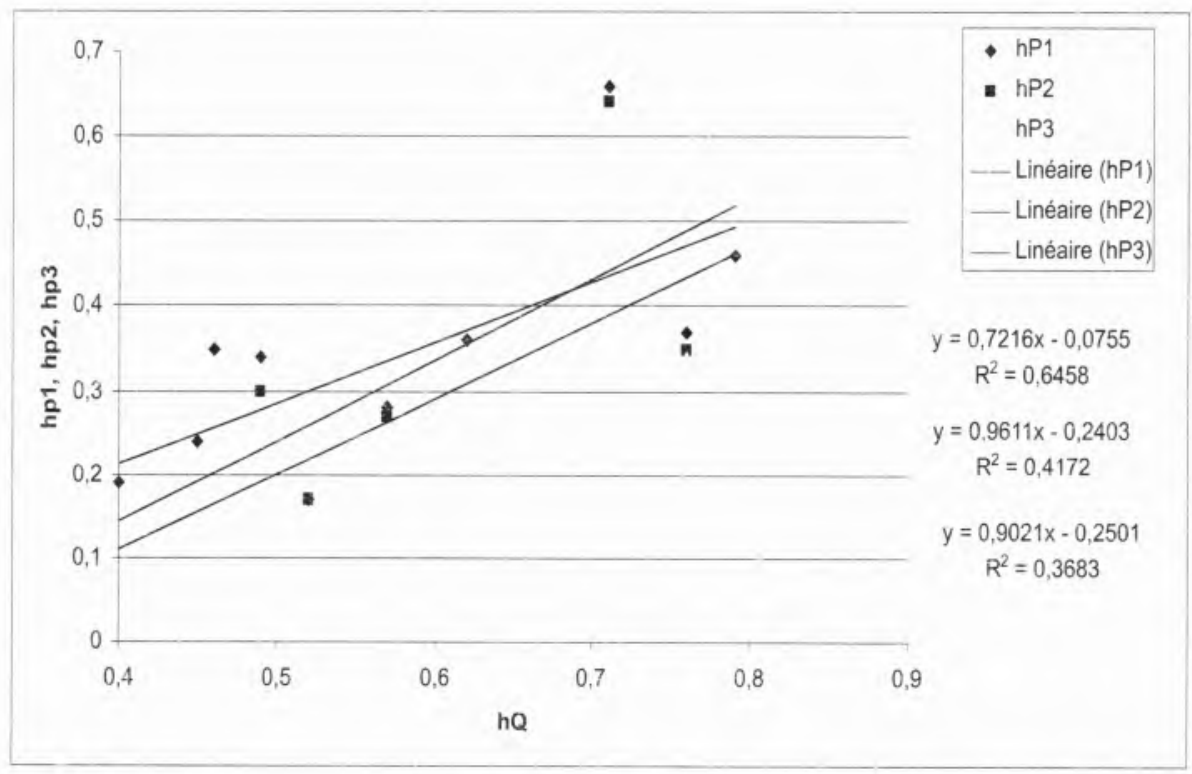

Fig. 3 - Variação da altura das princesas com a altura da rainha. Correlação razoável entre a altura da rainha e a da princesa primogénita. A correlação é muito mais significativa no subconjunto das cenas de oferenda dirigidas por Nefertiti $\left(R^{2}=0,93\right)$. 


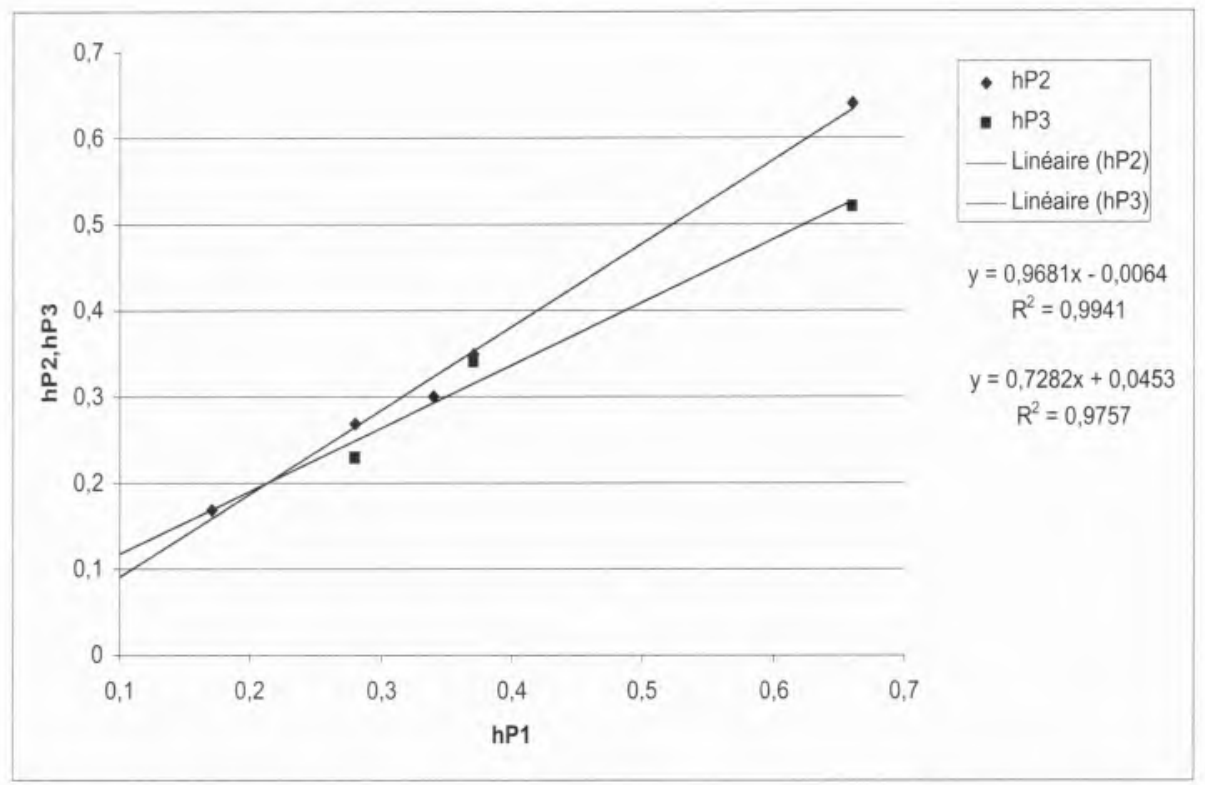

Fig. 4 - Variação da altura das princesas mais novas $\left(h_{P_{2}}, h_{P 3}\right)$ com a altura princesa mais velha $\left(h_{p_{1}}\right)$. Correlação muito forte entre a altura da primogénita e a das duas irmãs seguintes $^{(38)}$.

Contrariamente ao que seria de esperar, a correlação entre a altura do disco solar e a do rei é fraca. Cabe pois ao soberano o papel dominante em todas as representações. Existe, por outro lado, uma correlação bem definida entre a altura do rei e da rainha, o que não surpreende, porquanto já Krauss e Linckel (39) haviam estudado a relação entre vários parâmetros das cabeças do rei e da rainha (fig. A7), mostrarando que era constante, $k=0,7^{(40)}$. A análise fotogramétrica ${ }^{(41)}$ de dois bustos de Akhenaton e de Nefertiti, permitiu-Ihes ainda concluir, com uma probabilidade de $99,86 \%$, a quase identidade dos seus perfis (fig. A8). Parece, pois, haver uma entidade única e bissexuada no trono do Egipto, a qual exibe o seu aspecto masculino enquanto Akhenaton e feminino como Nefertiti. Em certos casos, os corpos podem mesmo sobrepor-se ${ }^{(42)}$.

Há também uma correlação entre a altura da princesa primogénita e as alturas das duas irmãs seguintes. O facto de a altura da rainha ser condicionada pela do rei e a altura da princesa pela da rainha ilustra bem a hierarquia existente na família real, hierarquia que se proclama urbi et orbi nas estelas do ano 6: 


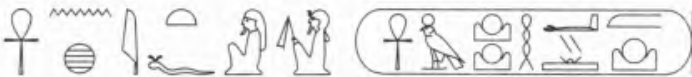

Th it.i enh Re-Hr-3hty h'y $m$ 3ht

(Tão certo como) vive meu pai, o vivo Ré-Horakhti, que rejubila no horizonte,

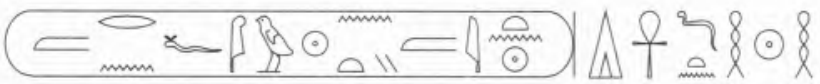

m rn.f (m) šw nty $m$ Itn di 'nh di Cnh $^{\mathrm{d}} \mathrm{t}$ nhh

no seu nome de "a luz que está no disco solar», o que dá a vida eternamente, para sempre,

₹

mh histy hr $(t) 3$ hmt-nsw hr hrdw(t).s nty rdit i3wy

(assim) o meu coração se deleita com a esposa real e as suas fiIhas ${ }^{(43)}$, o qual (o coração do rei) concederá uma avançada idade

\section{F。}

hmt-nsw wrt Nfr-nfrw-Itn Nfrt-ity 'nhti dt nhh

à grande esposa real, Neferneferuaton Nefertiti, que ela viva eternamente e para sempre,

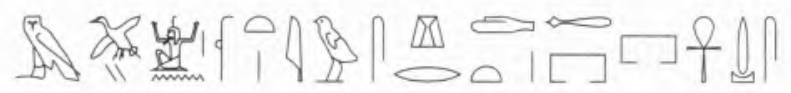

m p3y hh(w) n rnpt (w) iw.s hr drt pr- 3 Cnh wdi snb

nestes milhões de anos. Ela está sob a mão (a autoridade) do faraó, vida, força e saúde

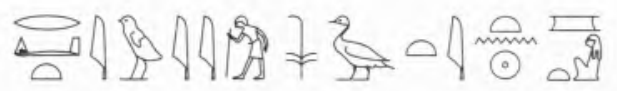

rdit i(3)wy s3t-nsw Mrit-Itn

e (ele também) concederá uma idade avançada à princesa Meritaton

$\Rightarrow$ ?ृि口:

s3t-nsw Mrkt-1tn n3yw s(dt)yw(.sn) iw hr drt t3 hmt-nsw

e à princesa Maketaton, suas filhas ${ }^{(44)}$, que estão sob a autoridade da esposa real(45). 
A relação primária verifica-se entre Akhenaton e Nefertiti. As fiIhas respondem perante a mãe e, embora acompanhem o pai em certas cerimónias, estão num nível de proximidade menor, como se vê na fig. A9.

\section{Conclusões}

O panorama artístico contemporâneo deste rei deve ser entendido como a continuação lógica, por vezes levada ao inaudito, de um movimento que é possível fazer remontar, pelo menos, ao reinado de seu pai, Amen-hotep III. A "arte de Amarna" tem duas fases distintas: a primeira, presente nos trabalhos do escultor Bek, é mais radical e a segunda, ligada ao escultor Tutmés, mais realista e apaziguadora. Devem-se-Ihe belíssimos retratos esculpidos de membros da família real e de cortesãos.

A representação deformada do corpo do rei poderia transcrever uma realidade física ou teológica, tal como parece transparecer nos hinos a Aton. Estudos muito recentes do ADN da múmia do KV55, considerada como pertencente a Akhenaton, não mostraram contudo que padecesse de uma qualquer disfunção.

A especificidade das representações plásticas do rei foi copiada pelos seus próximos como prova de adesão aos seus princípios religiosos ou por simples instinto de sobrevivência.

Em certos casos, as imagens de Akhenaton e da grande esposa real confundem-se, como se fossem uma realidade única.

As princesas reais distinguem-se das outras mulheres pelas suas cabeças alongadas, o que poderia resultar de práticas de deformação craniana, a respeito das quais não se encontraram provas, ou de alguma concepção teológica que não é evidente.

$\mathrm{O}$ estudo de um conjunto de cenas, envolvendo o casal régio e as filhas, mostrou que não deve ser posta de parte a ideia de um plano matemático comum a todas elas e fundamentado nas concepções ícono-teológicas do tempo. Aton não é a figura dominante mas sim Akhenaton. O rei condiciona a altura de Nefertiti e ela condiciona a das filhas. Esta relação hierárquica exprime-se igualmente num conjunto de estelas que delimitam Akhetaton e foram gravadas no ano 6. 


\section{ANEXO}

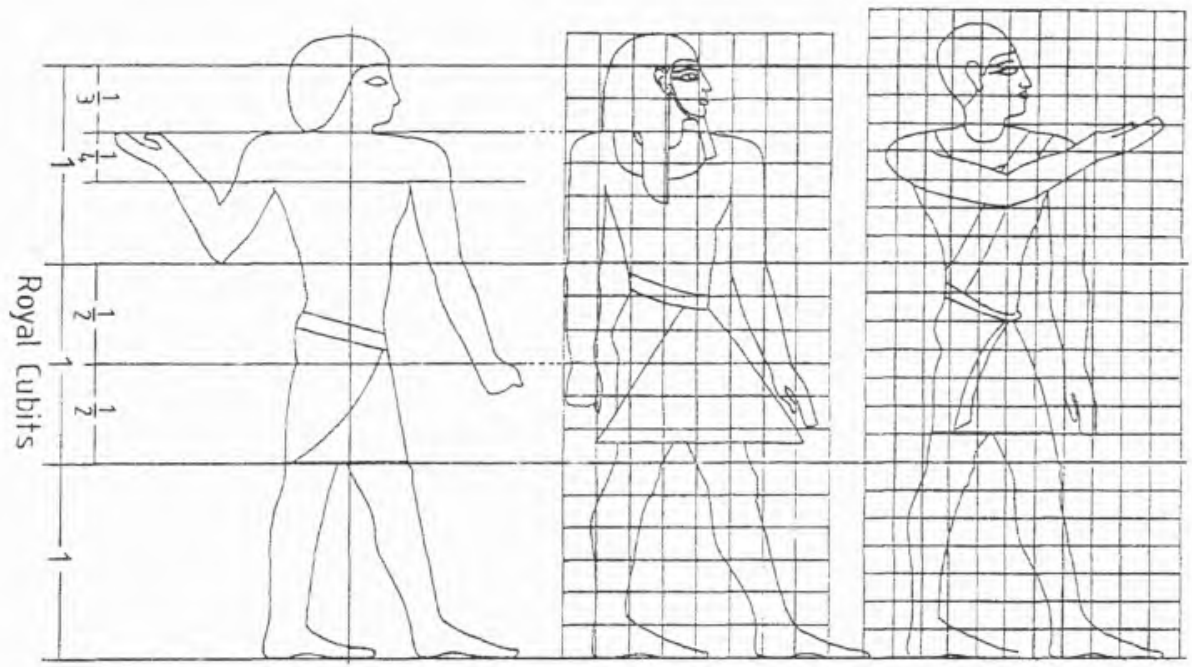

Fig. A1 - Desenvolvimento do sistema de proporções em quadrícula ${ }^{(46)}$.

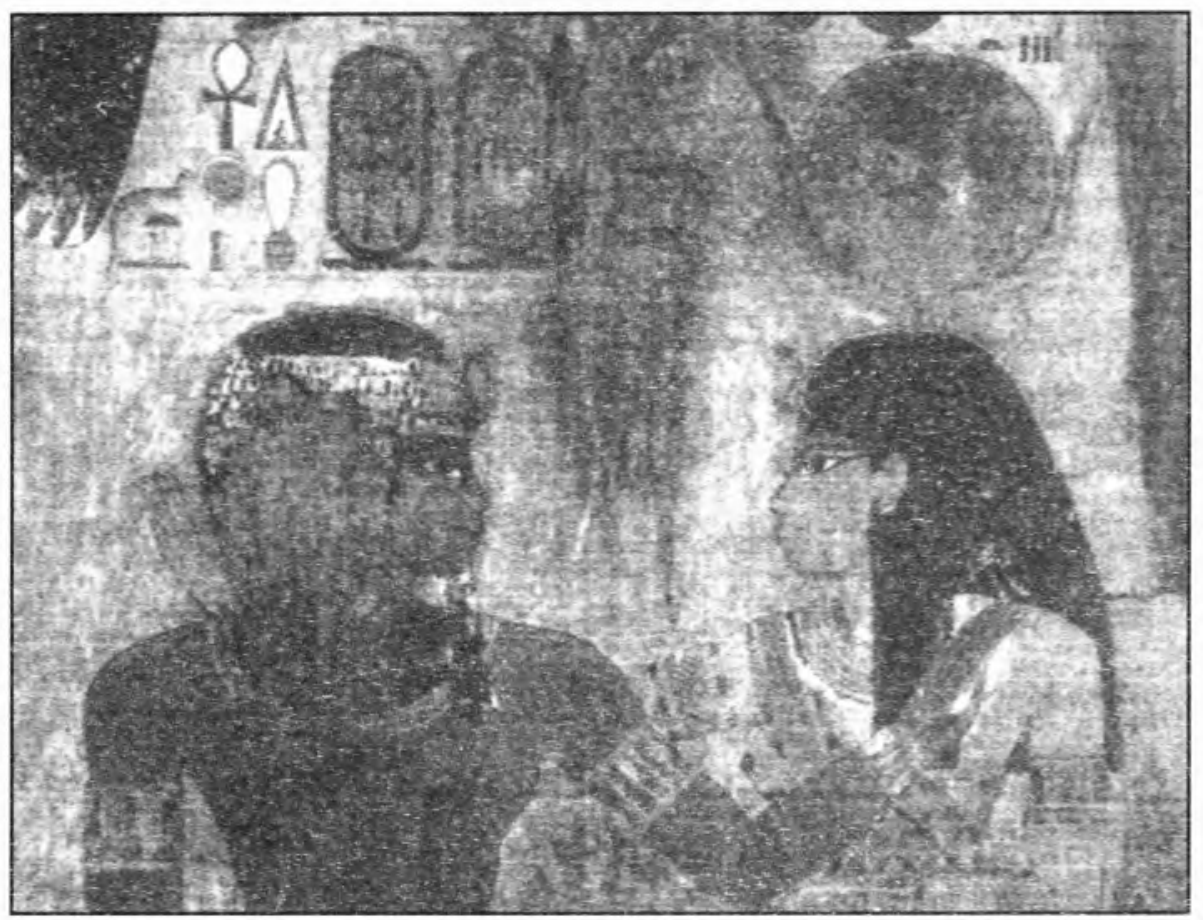

Fig. A2 - Amen-hotep III e a deusa Hathor. Pintura do túmulo real no Vale dos Reis. 

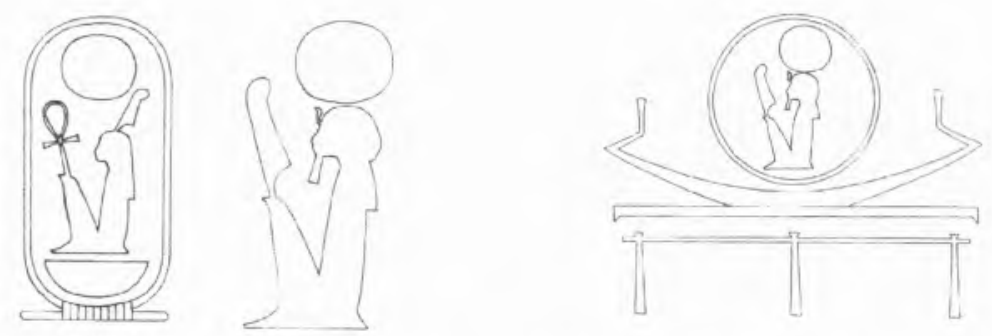

Fig. A3 - O prænomen de Amen-hotep III, Nebmaetré, dentro da tradicional cartela e a sua representação criptográfica. À direita - Representação criptográfica e elaborada do nome de Amen-hotep III, navegando na barca celestial, "Nebmaetré é o disco brilhante" (Neb-maet-Ré Iten-Tjehen).

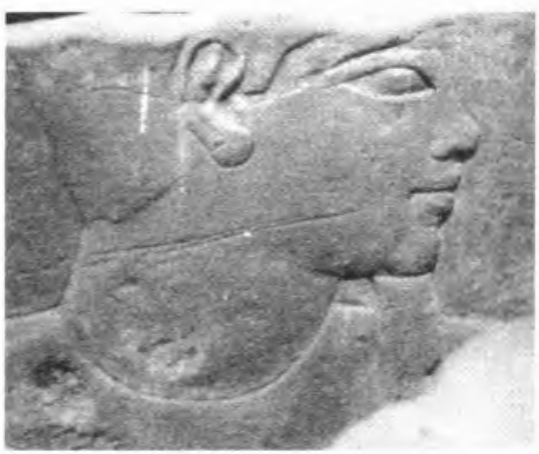

Fig. A4 - Akhenaton adolescente. Fragmento do décimo pilone do templo de Amon em Karnak. Fonds d'Égyptologie de la Societé d'Égyptologie de Genéve.
Fig. A5 - Colosso assexuado, eventualmente de Akhenaton, que foi encontrado em Karnak (Museu Egípcio do Cairo).

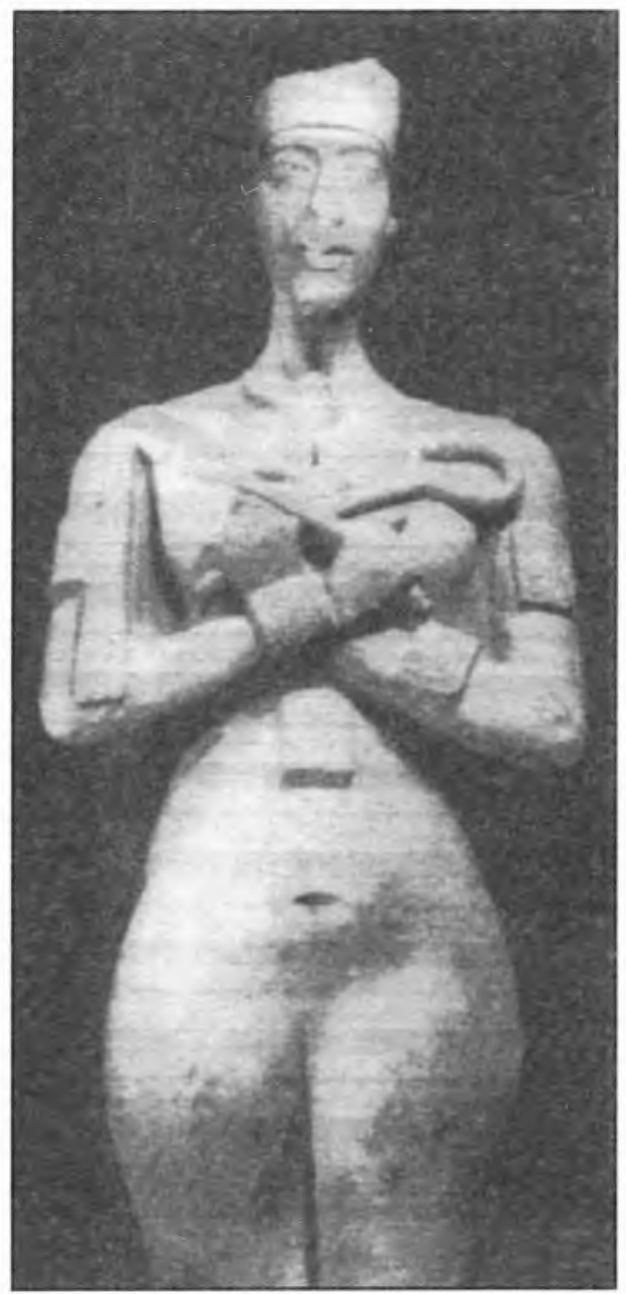



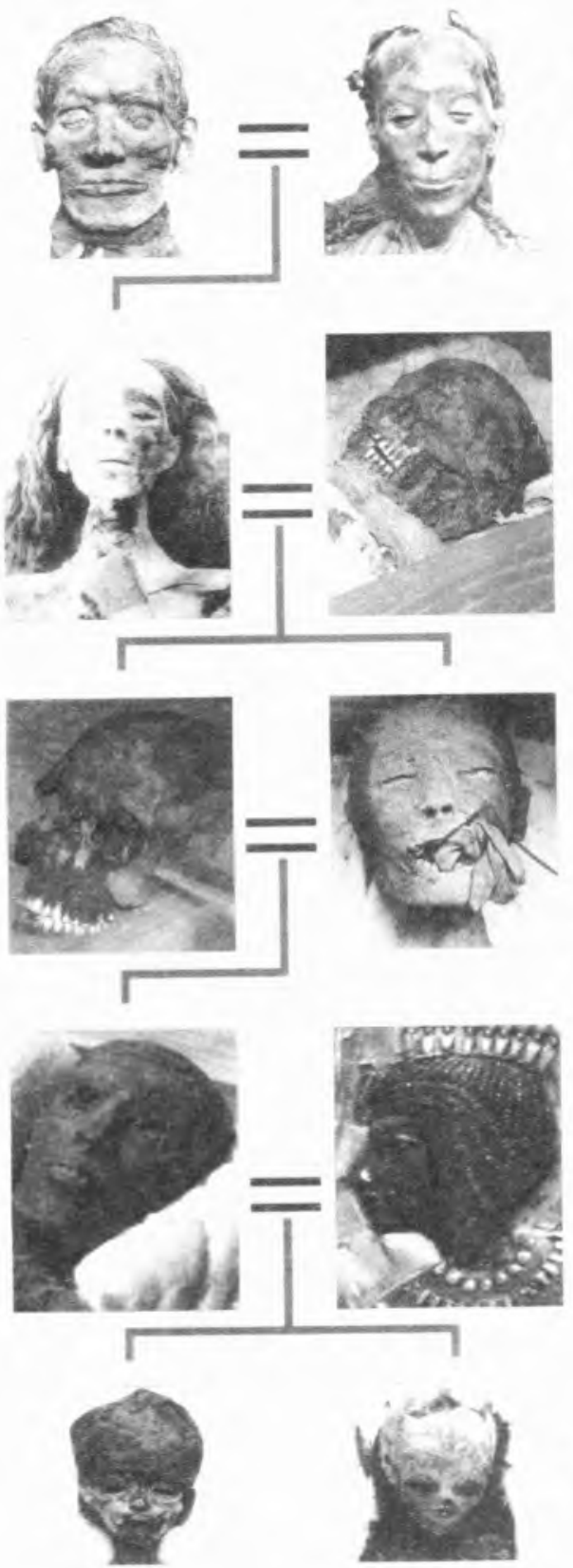

Yuya e de Thuya. As suas múmias foram descobertas em 1905 no KV46. Os testes mostraram que são os pais biológicos da rainha Tié

Tié e Amen-hotep III. As suas múmias foram encontradas em 1898 no túmulo de Amen-hotep II (KV35). A múmia de Tié não possuía qualquer identificação e foi durante muito tempo referida como "elder lady", chegando até a admitir-se que fosse Nefertiti. No entanto, a comparação do seu cabelo com a madeixa encontrada no túmulo de Tutankhamon mostrara já uma correspondência positiva.

Akhenaton e uma filha de Amen-hotep III. Foram pais de Tutankhamon.A múmia do rei foi encontrada no KV55 em 1907 e tomada durante muito tempo como pertencente a Semenkhkaré. A múmia da sua irmã, anteriormente conhecida com "younger lady" foi encontrada no KV35 e erradamente identificada por Joan Fletcher como Nefertiti. $\mathrm{O}$ seu verdadeiro nome não é conhecido.

Tutankhamon e Ankhesenamon, filha de Akhenaton e Nefertiti. O corpo do jovem rei foi descoberto em 1922 por Howard Carter no KV62 e a múmia da sua esposa e meia-irmã encontrada no KV21. Estava em muito mau estado de conservação.

Múmias de dois fetos não identificados. Os testes mostraram ser filhos de Tutankhamon

Fig. A6 - Árvore genealógica de Tutankhamon, de acordo com os testes de ADN efectuados em 2010, pela equipa de Zahi Hawass ${ }^{(47)}$. 

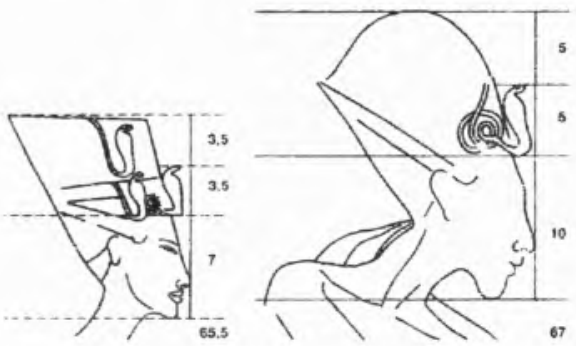

$$
\begin{aligned}
& n_{1} / n_{2}=0,7 ; p_{1} / p_{2}=0,7 ; q_{1} / q_{2}=0,7 ; r_{1} / r_{2}=0,7 \\
& \left.n_{1}(i=1,2) \quad \text { (rei: } i=1, \text { rainha: } i=2\right)
\end{aligned}
$$

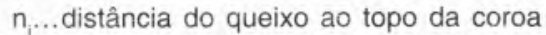

$p_{i}$... distância do queixo à uraeus

$q_{1}$.... altura da uraeus

$r_{1}$... distância da uraeus ao topo da coroa

Fig. A7 - Medição de parâmetros nas cabeças de Akhenaton e de Nefertiti. Relevo do túmulo de Ai em Amarna ${ }^{(43)}$.
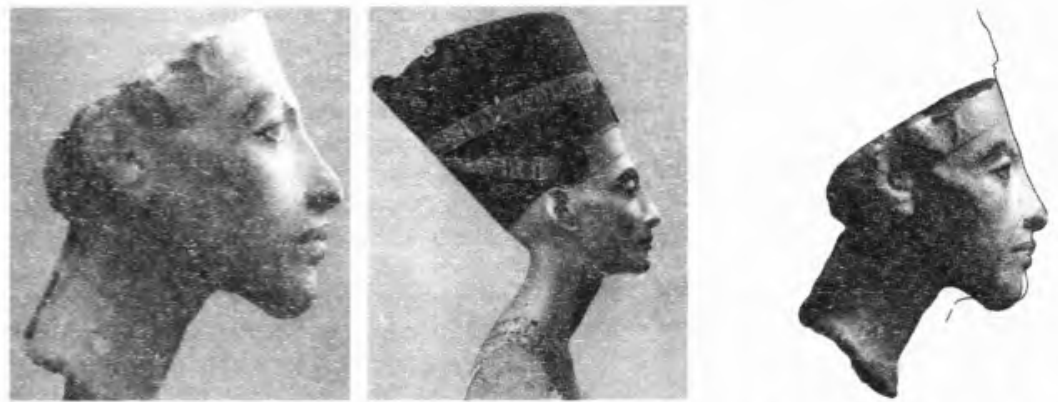

Fig. A8 - Sobreposição dos perfis de Akhenaton e Nefertiti em dois bustos do Museu de Berlim(49).

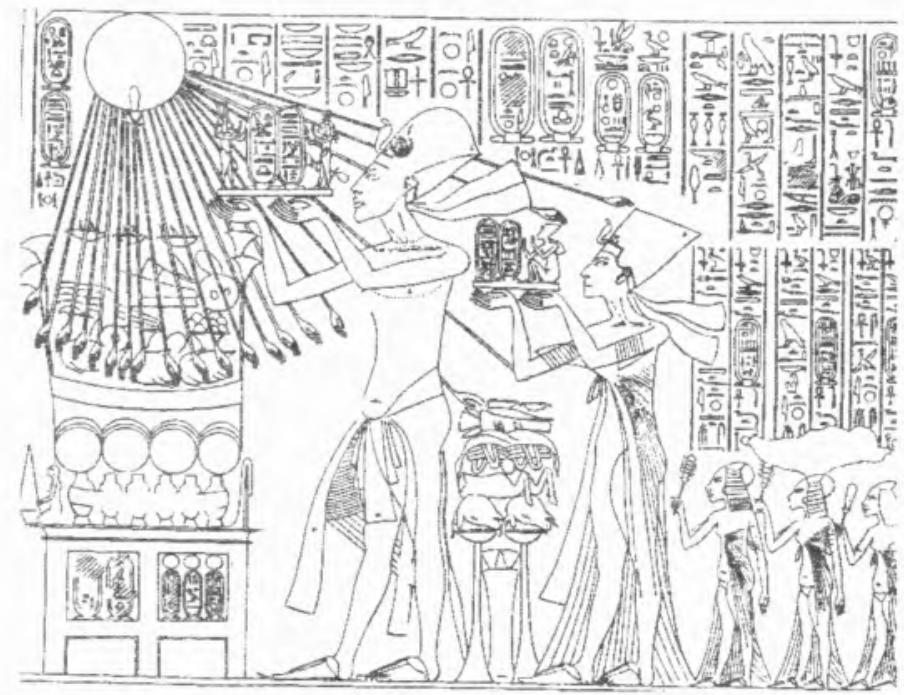

Fig. A9 - Akhenaton e Nefertiti fazendo uma oferenda a Aton, na companhia de três filhas. Túmulo de Api, TA10, em Amarna. O rei ergue uma cartela do deus, ladeada pelos gémeos Chu e Tefnut, tradução divina do casal soberano. Nefertiti oferece também uma cartela e a sua própria imagem, talvez corporizando Maet. 


\section{Notas}

(1) Nas paredes do seu túmulo, Parennefer ergue os braços imitando o signo A28, $h$ \% , “júbilo". Ver WILKINSON, Reading Egyptian Art, p. 27.

(2) BAINES, e MÁLEK, Atlas of Ancient Egypt, p. 61.

(3) ROSSI, Architecture and Mathematics in Ancient Egypt, p. 82.

(4) FREED et al, Pharaohs of the Sun, p. 113.

(5) Ver ARAÚJO, "Quadrícula", Dicionário do Antigo Egipto, p. 725.

(6) Mais concretamente, da região compreendida entre o joelho e a sobrancelha da figura.

(7) As franjas superiores da classe dos funcionários: civis, sacerdotes e militares.

(8) JOHNSON, "Monuments and monumental art under Amen-hotep III", em O'CONNOR e CLINE, Amen-hotep III, p. 86.

(9) Como o colar chetbiu, o "ouro da honra": colar de ouro oferecido pelo rei a funcionários ou generais, como prémio pelos serviços prestados, o colar wah, associado a Osíris, bolsas ornamentais em forma de cauda de falcão e cobras com o disco solar.

(10) Epigraphic Survey (1980) 43, pl. 24, apud ALDRED, op. cit., p. 87.

(11) Estela de Men e Bek em Assuão, apud TYLDESLEY, Nefertiti, Egypt Sun Queen, p. 92

(12) SAMSON, Nefertiti and Cleopatra. Queen-monarchs of Ancient Egypt, p. 22, apud TYLDESLEY, Nefertiti, Egypt Sun Queen, p. 118.

(13) Note-se que a mesma autora tinha considerado, anos antes, poder tratar-se de um homem SAMSON, Amarna, City of Akhenaten and Nefertiti, p. 23, apud TYLDESLEY, op. cit., p. 101.

(14) TYLDESLEY, op. cit., pp. 102-103.

(15) Autor do celebérrimo busto de Nefertiti encontrado em Amarna e actualmente no Museu Egípcio de Berlim.

(16) ARNOLD, The Royal Women of Amarna, p. 55.

(17) Estariamos, deste modo, perante uma espécie de "tribo de Akhenaton" que, à semeIhança dos motards, hippies e punks se identificaria, enquanto grupo, mediante sinais específicos? Veja-se a representação do escultor Bek e de sua esposa, actualmente no Museu Egípcio de Berlim.

(18) MONTSERRAT, op. cit., p. 57.

(19) FLAVIO JOSEFO, Contre Apion XV, 96, René Harmand (trad.). Ver o site http:/l remacle.org/bloodwolf/historiens/Flasose/Apion1.htm de 30-08-2005. Ver igualmente ALDRED, Akhenaten, king of Egypt, p. 231.

(20) PETRIE, Tell el Amarna, pp. 38-39, apud TYLDESLEY, Nefertiti, pp. 96-97.

(21) WEIGALL The life and times of Akhnaton, p. 61.

(22) BURRIDGE, Journal of the Society for the Study of Egyptian Antiquities, 23 (1993), p.70 apud REEVES, Akhenaten, Egypt's false prophet, pp. 150-151.

(23) REEVES, Akhenaten, Egypt's false prophe, p. 151.

(24) BIÉTRY-RIVIĖRRE, Le Figaro Magazine, 20/Fév. 2010; Science et Vie, n. 1111, Avril 2010, pp. 20-29. 
(25) Journal of the American Medical Association (3003) n. ${ }^{\circ}$ 7, February 17, 2010, tal como é mencionado na nota distribuida à imprensa pelo Dr. Hawass. Ver Ancient Egypt (10) n. ${ }^{2}$, April/May 2010, pp. 52-55.

(26) Pensava-se corresponder a um homem entre 20 e 25 anos, talvez Semenkhkaré.

(27) Crescimento anormal do peito masculino por desequilibrio hormonal ou acumulação de gordura.

(28) Fechamento prematuro das suturas ósseas da cabeça. Leva à deformação do crânio e pode causar perturbações na visão.

(29) FLETCHER, The Search for Nefertiti, Londres: Hodder and Stoughton, 2004. Também foi considerada mãe de Tutankhamon. Ver GABOLDE, D'Akhenaton à Toutânkhamon, pp. 18-20.

(30) HUSSEIN, F. and HARRIS, J. E., "The skeletal remains from tomb n. 055 ", in Fifth International Congress of Egyptology, October 29-November 3, Cairo, 1988, pp. 140-141. Para mais informação, ver GABOLDE, Marc, op. cit., pp. 87-98

(31) Ver, por exemplo, ALDRED, C., Akhenaten, King of Egypt, pp. 169-182; MOSELEY, S., Amarna, the missing evidence, pp. 92-105.

(32) MORAN (ed. e trad.), The Amarna Letters, p. 17. De acordo com o cos-tume, Amenhotep IV herdou Tadukhepa, última esposa de seu pai, por morte deste.

(33) Excepcionalmente, também Nefertiti aparece a fazer oferendas a Aton, na companhia da filha mais velha.

(34) Na realidade, Amen-hotep III tinha falecido havia já muito tempo.

(35) Se a altura do Sol for a variável independente, teremos relações do tipo $h_{x}(x=K, Q$, $p)=f\left(h_{s}\right)$. Se for a altura do rei, elas tomarão a forma $h_{y}(y=S, K, p)=f\left(h_{k}\right)$ Onde $h$ é, respectivamente, a altura do $\operatorname{Sol}(S)$, do rei $(K)$, da rainha $(Q)$ ou das princesas $(p)$.

(36) Ibidem, pp. 176-182.

(37) Medida através do "coeficiente de correlação" $R^{2}$. Essa correlação existe se $1 e$ "R e" 0,5.

(38) Não há valores suficientes para quantificar possiveis relações com as outras filhas de Nefertiti.

(39) KRAUSS e LINCKEL, "Les représentations de Nefertiti e d'Akhenaton sont-elles réalistes?", Akhénaton et l'époque amarnienne, pp. 137-144.

(40) Próxima da razão entre as suas alturas determinada, no presente trabalho, para as cenas de oferenda dirigidas pelo rei, $k=0,76 \pm 0,09$.

(41) Software que permite planificar vistas de objectos tridimensionais.

(42) Representação do festival do ano 12 , nos túmulos dos funcionários Meriré (II) e de Huia, em Amarna.

(43) 21 h) hrdwt.s, filhas dela. Não se compreende o determinativo que aparece na estela que, para além desta, apresenta uma outra mulher na postura equivalente ao signo masculino ${ }^{2}$. Optou-se por ignorar este facto. Repare-se também que Nefertiti é designada por "esposa real" e não por "grande esposa real». Propositadamente ou erro do escriba?

(44) |⿴囗十, sdtyw, filhos. 
(45) Uma vez mais, Nefertiti não é designada por "grande esposa real».

(46) Segundo LEGON (DE 35, fig.1), apud ROSSI, Architecture and Mathematics in Ancient Egypt, p. 82.

(47) Ancient Egypt (10) n. 5, April/May 2010, p. 54.

(48) KRAUSS e LINCKEL, op. cit., p. 137.

(49) Idem, ibidem, pp. 141-142.

\section{Bibliografia consultada}

ALDRED, Cyril, Akhenaton, king of Egypt, Londres: Thames and Hudson, 1999.

ARMIJO, Teresa, Nefertiti, Madrid: Edimat Libros, 2005.

ARAÚJO, Luís Manuel de (dir.), Dicionário do Antigo Egipto, Lisboa: Editorial Caminho, 2001.

ARNOLD, Dorothea (ed.), The Royal Women of Amarna, Nova lorque: The Metropolian Museum of Art, Harry N. Abrams, Inc., 1997.

BAINES, John e MÁLEK, Jaromir, Atlas of Ancient Egypt (edição revista), Cairo: The American University in Cairo Press, 2005.

CARREIRA, Paulo, Akhenaton, uma perspectiva teo-histórica, dissertação apresentada para a obtenção do grau de mestre em História e Cultura Pré-Clássica, Lisboa: Faculdade de Letras da Universidade de Lisboa, 2007.

DAVIES, Norman de G., The Rock Tombs of el-Amarna, vols. I-III, re-print, Londres: The Egypt Exploration Society, 2004.

DODSON, Aidan e HILTON, Dyan, The Complet Royal Families of Ancient Egypt, Cairo: The American University in Cairo Press, 2005.

FLETCHER, Joann, The Search for Nefertiti, Londres: Hodder and Stoughton, 2004.

FREED, Rita, Markowitz, Yvonne, D'AURIA, Sue H. (eds.), Pharaohs of the Sun, Boston: Museum of Fine Arts in association with Bulfinch Press, Little, Brown and Company, 2000.

GABOLDE, Marc, D'Akhenaton à Toutânkhamon, Université Lumière-Lyon 2, Institut d'Archéologie et d'Histoire de l'Antiquité, Paris: Diffusion de Brocard, 1998.

HAWASS, Zahi, Tutankhamon and the Golden Age of the Pharaohs, Washington D. C.: National Geographic, 2005.

LABOURY, Dimitri, Akhénaton, Paris: Pygmalion, 2010.

LALOUETTE, Claire, Thèbes ou la naissance d'un empire, Paris: Flammarion, 1995.

MONTSERRAT, Dominic, Akhenaten. History, Fantasy and Ancient Egypt, Londres, Nova lorque: Routledge, 2003.

MORAN, William L. (ed. e trad.), The Amarna Letters, Baltimore, London: The John Hopkins University Press, 1992.

MOSELEY, Sue, Amarna. The missing evidence, Calshot: The Peach Pixel, 2009.

O'CONNOR, David e CLINE, Eric H. (eds.), Amen-hotep III. Perspectives on His Reign, Ann Arbor: The University of Michigan Press, 2001.

REEVES, Nicholas, Akhenaten, Egipt's false prophet, Londres: Thames and Hudson, 2001. 
REEVES, Nicholas, The Complete Tutankhamun. The king, the tomb, the royal treasure, Londres: Thames \& Hudson, 1997.

ROSSI, Corinna, Architecture and mathematics in Ancient Egypt, Cambridge: Cambridge Uni-versity Press, 2004.

SALES, José das Candeias, As Divindades Egípcias. Uma chave para a compreensão do Egipto antigo. Lisboa: Editorial Estampa, 1999.

TYLDESLEY, Joyce, Chronicle of the Queens of Egypt. From early dinastic times to the death of Cleopatra, Londres; Thames and Hudson, 2006.

WEIGALL, Arthur, the Life and Times of Akhenaton, Pharaoh of Egypt, Nova lorque: G. P. Putnam's Sons, 1923.

WILKINSON, Richard H., Reading Egytian Art, Londres: Thames and Hudson, 1996.

WILKINSON, Richard H., Symbol \& Magic in Egyptian Art, Londres: Thames \& Hudson, 1999.

\section{Artigos}

Ancient Egypt (10) n.5, April/May 2010.

ARAÚJO, Luís Manuel de, "Aton", Dicionário do Antigo Egipto, Lisboa: Editorial Caminho, 2001, pp. 122-125.

ASSMANN, Jan, Theological responses to Amarna, Penn State University, 2001.

ASSMANN, Jan, "Akhanyati's Theology of Light and Time", The Israel Academy of Sciences and Humanities Proceedings, vol. VII, n. ${ }^{2} 4$, 1992, pp. 143-176.

BIÉTRY-RIVIĖRE, Eric, Le Figaro Magazine, 20/Fév. 2010.

GABOLDE, Marc, «La postérité d'Amen-hotep III, Akhenaton et l'époque amarnienne, 2005, pp. 13-33.

GABOLDE, Marc, "Pour qui fut confectionné le mobilier funéraire de Toutânkhamon?", Akhenaton et l'époque amarnienne, 2005, pp. 273-286.

KRAUSS, Rolf e LINCKE, Eliese Sophie, "Les représentations de Néfertiti et Akhénaton sont-elles réalistes?", Akhenaton et l'époque amarnienne, 2005, pp. 135-143.

Science et Vie, n.1111, Avril 2010.

ZIVIE, Alain, "À propos de la tombe de Maïa, nourrice de Toutânkhamon", Akhenaton et l'époque amarnienne, 2005, pp. 287-300. 